\title{
The Service Dominant Strategy Canvas: Towards Networked Business Models
}

\author{
Egon Lüftenegger ${ }^{1}$, Paul Grefen ${ }^{1}$, and Caren Weisleder ${ }^{2}$ \\ ${ }^{1}$ School of Industrial Engineering at Eindhoven University of Technology \\ P.O Box 513, 5600 MB Eindhoven, The Netherlands \\ \{e.r.luftenegger, p.w.p.j.grefen\}@tue.nl \\ ${ }^{2}$ De Lage Landen International B.V. \\ P.O Box 652, 5600 AR, Eindhoven, The Netherlands \\ $\{c . w e i s l e d e r\}$ @delagelanden.com
}

\begin{abstract}
Service orientation, customer focus and collaboration between firms are profoundly changing the way of doing business. Marketing scholars are the first academics to conceptualize these changes under a new mindset, known as the Service Dominant Logic. However, management constructs are needed to apply this mindset to the business environment. Therefore, we have developed a new conceptual model of a Service Dominant Strategy with a visual representation in the form of a canvas. Our model is constructed by integrating current definitions of a Service Dominant strategy and by confronting them with traditional strategies. The model facilitates the design of Service Dominant strategies by answering the questions associated with fifteen elements. Experimental application of our approach in several industry domains shows the importance of both strategic level design and Service Dominant thinking.
\end{abstract}

Keywords: service dominant strategy, service dominant logic, business canvas, strategy model, service science.

\section{$1 \quad$ Introduction}

Service Science is an interdisciplinary area of study addressing the challenge to become more systematic about innovating in services. There is a strong industry and academic shift in interest towards services. However, most academics and industry professionals are still working under the manufacturing paradigm rather than the service paradigm [1]. This slow change has a negative impact on service innovation. The ability to change is constrained by the dominant logic of manufacturing, which is Goods Dominant. This issue that prevents the adoption of new ways of doing business is known as the dominant logic trap: the prevailing dominant logic act as a filter in a funnel that prevents the ideation and adoption of business concepts that do not fit with the current dominant logic [2], [3].

A new innovative mindset that addresses this change towards a service dominant economy focused at the network level is known as the Service Dominant Logic (SDL) [4]. This theoretical foundation has been developed by marketing scholars and 
recognized as a key theory for the advancement of Service Science. However, this theory as originally stated is difficult to understand and communicate [5]. Management constructs are needed to drive businesses development under the SDL. We need to focus on the organizational change and business models that will make serviceoriented technologies and collaborative networks the main drivers to solve business problems. Hence, the strategy is the first management construct that we need to communicate this dominant logic change to decision makers. Nowadays, there is a lack of management tools developed specifically to design service dominant strategies. Current tools, like the Balanced Scorecard [6], have been constructed by using the manufacturing mindset in which improving the efficiency of the firm from an internal perspective is desired [7]. In today's complex and dynamic business environment, we need management tools that emphasize service orientation and networked collaboration from a service dominant perspective on doing business.

In this paper, we focus on a management tool that facilitates the design of strategies for the Service Dominant landscape. We have developed this conceptual model by reviewing existing research on SDL at the strategic level and by confronting it with traditional business strategies developed by business and marketing scholars. This approach has been chosen to have traditional strategic concepts acting as a bridge between the current dominant mindset and the new Service Dominant mindset. Our conceptual model takes the canvas approach as a visual representation to communicate and design. This approach has emerged from the Information Systems domain in academia and currently has been widely accepted in industry [8].

This paper is structured as follows: In Section 2, we identify and analyze the background research on SDL at the strategic level. In section 3, we establish a strategic bridge with traditional strategies to identify the elements of a Service Dominant strategy. In Section 4, we visualize the Service Dominant strategy and discuss the results of prototype application of the canvas in several industrial settings. We end this paper with conclusions.

\section{Analysis of Background Research on SDL}

In this section we study the literature in which a strategic view on the SDL is developed. We select the research by tracking the original authors of the SDL, and by searching Google Scholar using the keywords "service dominant strategy" and "service dominant strategic".

Firstly, the "competing through service" research argues that to compete effectively through service, the entire organization should view the market and itself with a SDL [9]. In this research, the SDL authors define derived propositions from the original foundational premises of the SDL as strategy. One of these derived proposition is "Firms can compete more effectively through the adoption of collaboratively developed, risk-based pricing value propositions".

Secondly, the "strategic service orientation" research is focused on the interactions with the customer [10]. The author defines his strategic approach on service by 
interactions. One of these interactions is stated as "Individuated interaction with an emphasis on understanding individual customers".

Finally, the "constructing a service dominant strategy" research complements the previous approaches by bringing the perspective of economics [11]. In this work the authors develop a Service Dominant strategy with a start-up company as real case scenario. In this research, the strategy is presented as goods dominant versus service dominant defined by statements like: "rigid versus flexible organizational boundaries". For our purposes, we take the service dominant aspect only: flexible organizational boundaries.

We identify as Service Dominant strategic statements the derived propositions of the SDL defined in the "strategic service orientation" research, the interactions defined in the "strategic service orientation" research and the service dominant aspects of "constructing a service dominant strategy" research. In Section 3, we use the background research to identify the elements of a Service Dominant Strategy. The complete list on the Service Dominant strategic statements is presented in [12].

\section{$3 \quad$ Bridging Service Dominant and Traditional Strategies}

In this section, we identify a conceptual bridge between traditional strategies and the Service Dominant research efforts discussed in Section 2. This conceptual bridge aims to facilitate the communication of a Service Dominant strategy by using traditional strategic concepts. The conceptual bridge is being developed by analyzing five traditional strategies identified and classified in [13] as being developed from business and marketing scholars. Firstly, within the strategies developed by business scholars we can distinguish: industry-based, competence-based and resource-based. Secondly, within the strategies developed by marketing scholars we can distinguish: market-oriented and relational marketing [13].

We establish a conceptual bridge with three of the five traditional strategies. Firstly, we discuss why we discard the industry-based and market-oriented strategies. Secondly, we explain the how we establish a strategic bridge between the service dominant strategy and the competence-based, relational marketing and resource-based strategies.

Firstly, we discard the industry-based strategy as a strategic bridge; because Porter's approach is more suitable for the manufacturing mindset with the value chain approach rather the Service Dominant mindset and its value network focus [19]. Secondly, we discard the market-oriented strategy as strategic bridge, because the Service Dominant mindset focuses on the individual relationship with "the customer" rather than the market as a whole.

We establish below a strategic bridge with three traditional strategies: competencebase, relational marketing and resource-based. The strategic bridge is being developed by conceptualizing the Service Dominant strategy as business competences, market relationships and business resources elements. These elements are identified from the background research on the SDL depicted in Section 2. We illustrate with an example 
our line of reasoning on how we identify the elements for each strategic bridge. However, the identification process for all the elements is presented in [12].

Business Competences. The competence-based strategic view suggests that to achieve competitive advantage firms should identify, seek develop, reinforce, maintain and leverage distinctive competences [14]. Grant argues that resources are not a source of competitive advantage by their own. In line with this reasoning, capabilities are the source of competitive advantage. Hamel and Prahalad use the term "core competences" to describe the central strategic capabilities of a firm to achieve competitive advantage [15]. Hence, competitive advantage can be achieved by distinctive competences. We can recognize distinctive competences as enablers of a Service Dominant strategy by answering the question "How do we enact our business relations in a Service Dominant business?" For example, we can identify the Co-creation and Co-production business competence elements from the "competing through service" research by analyzing the Service Dominant strategic statement: "Firms gain competitive advantage by engaging customers and value network partners in co-creation and co-production activities". Furthermore, we can group the business competences within value and collaboration:

The Value group contains the elements related with our proposition to our primary stakeholders from the value-in-use and the pricing perspectives. Firstly, Co-creation is about what we are enabling as value-in-use by delivering solutions with our primary stakeholders. Secondly, Risk-based Pricing is based on transitive risk with our primary stakeholders in our network. Moreover, the pricing mechanism should be based on the risk of actors that are participating co-producing the solution.

The Collaboration group contains the networked competences that we need to establish with our stakeholders for doing business. Firstly, Co-production is about how we create with our stakeholders in a collaborative way. This co-production is achieved by including all the stakeholders in the production of our solution-centered approach defined as value-in-use. Secondly, Service Integration is about how and why we integrate the business processes between all the stakeholders involved in our collaboration. This service integration is achieved by enabling the composition and orchestration of business processes to achieve the best solution that maximizes the value-in-use of all our stakeholders. Thirdly, Knowledge Sharing is about how and why we need to share knowledge. Moreover, knowledge sharing is achieved by capturing, processing and distributing the information related with value-in-use with all our stakeholders.

Market Relationships. The relational marketing strategic view suggests that to achieve competitive advantage, firms should develop a relationship portfolio with stakeholders such as customer, suppliers, employees and competitors [14]. Competitive advantage can be achieved by distinctive relational approaches. Moreover, the shift of the SDL towards "marketing with" the customer implies a relationship. We can recognize distinctive market relationships as enablers of a Service Dominant strategy by answering the question "How do we relate with our business environment in a Service Dominant business?" For example, we can identify the Empowerment 
relationship element from the strategic service orientation" research by analyzing the service dominant strategic statement: "Empowered interaction with an emphasis on enabling customers to shape the nature and/or content or exchange". Furthermore, we distinguish between endogenous an exogenous market relationships:

The Endogenous group contains the inside-out relationship elements that start from inside the company to the outside world. Firstly, Contextually Individuated is about how we customize our relationship with the customer. This contextualization is achieved by understanding the needs of the customer that maximize the value-in-use. Secondly, Empowerment is about how we enable our collaborators to participate. The firm should facilitate the active role of the customer in the co-production process by taking customer input. Moreover, this empowerment should also be established with other stakeholders of our collaborative network.

The Exogenous group contains the relationship elements that we need to establish with the outside world. Firstly, Bidirectional is about how we communicate with the external parties. This interaction facilitates conversation and dialog by co-producing and co-creating with the customer. Secondly, Ethical Mutual Benefit is about how we share with our collaborators. This relationship is established by a mutual gain for all the actors in the business collaboration. Thirdly, Flexible Organizational Boundaries is about how we establish our collaborative network. This relationship is established by being flexible through the inclusion of multiple actors for the enactment of valuein-use. This relationship minimizes the barriers between firms to co-produce service offerings.

Business Resources. The resource-based strategic view suggests that a firm possess resources to achieve competitive advantage and superior long-term performance [14]. The term resource is variously defined in the resource-based view literature. We take Grant's resource definition, because he distinguishes between resources and capabilities. A resource can be defined as the inputs or factors available to a company through which it performs its operations or carries out its activities [15]. We identify business resources as enablers of a Service Dominant strategy by answering the question "What ingredients do we need to enact our Service Dominant strategy?" For example, we can identify the Employees business resource element from the "competing through service" research by analyzing the Service Dominant strategic statement: "Firms that treat their employees as operant resources will be able to develop more innovative knowledge and skills and thus gain competitive advantage". Furthermore, we can group the business resources within actors and infrastructures:

The Actors group contains the business resources who participate in the service dominant business. Firstly, the Customer is an actor that meets the profile of an active customer. The customer, as an individual rather than a group, participates by determining the value-in-use and co-producing the desired solution. The customer is the main stakeholder in the determination of value-in-use, because he is the actor that will use the solution. By involving the customer we can get knowledge related with their needs in an active manner. Secondly, the Partners are actors that meet the profile of an active partner. The partners participate in the co-production of the solution for the established value-in-use. Moreover, engaging network partners in co-production 
activities enable the firm to gain competitive advantage. Thirdly, the Employees are actors that meet the profile of an active employee that is willing to understand what is valuable for the customer. Employees are a source of customer knowledge and understanding. They participate in the co-production of the solution for enabling value-inuse.

The Infrastructures group contains what resources we needed to develop a service dominant business. Firstly, the Service Flows are the activities that define our valuein-use proposition. Service flows, acting as cross-organizational business process oriented to the customer, are needed to enable the collaboration and co-production. Secondly, the Information Technologies are the enablers that facilitate the collaboration and the enactment of our value-in-use proposition. Moreover, Information Technologies increase the likelihood of cross-organizational and customer collaboration.

\section{The Service Dominant Strategy Canvas}

In this section, we present our canvas as a management tool to facilitate the design of Service Dominant strategies by using the elements and categories identified in Section 3. We use the canvas approach, inspired by the success of the Business Model Canvas, which is used by practitioners due to its rich visual approach [8].

Figure 1, shows the resulting Service Dominant Strategy Canvas that facilitates the design of a service dominant strategy by answering the questions associated for each of the fifteen elements that we have identified and categorized before. As shown in Figure 1, the three rectangular main columns named market relationships, business competences and business resources are the strategic bridges between traditional and service dominant strategic concepts. Each main column has two groups represented by rounded rectangular boxes that contain the Service Dominant elements represented by a circular icon and a rectangular label with their associated question below. These questions facilitate the interaction and communication with the participants in a structured and active manner.

As shown in Figure 1, the business competences column is located in the middle within the Service Dominant Strategy Canvas. We place this strategic pillar in the center to emphasize the value and collaboration groups. These two groups establish our strategic context for the understanding and design of a Service Dominant strategy.

We have tested our Service Dominant Strategy Canvas in three session with innovation managers and strategists within an information logistics company, an asset-based financial services provider and an international car leasing company. These industries currently are very asset oriented, making a perfect scenario to test the tool: a change in dominant logic is sought. The testing process is depicted as follows: firstly, we have presented the canvas with an explanation of all their elements using a well-known highly Service Dominant sample scenario. Secondly, we have asked the participants to design a Service Dominant strategy for their company by using the canvas. Each session was guided by a facilitator that knows the business of the company, the researcher who asked the strategic canvas questions and a senior manager for each industry setting. 


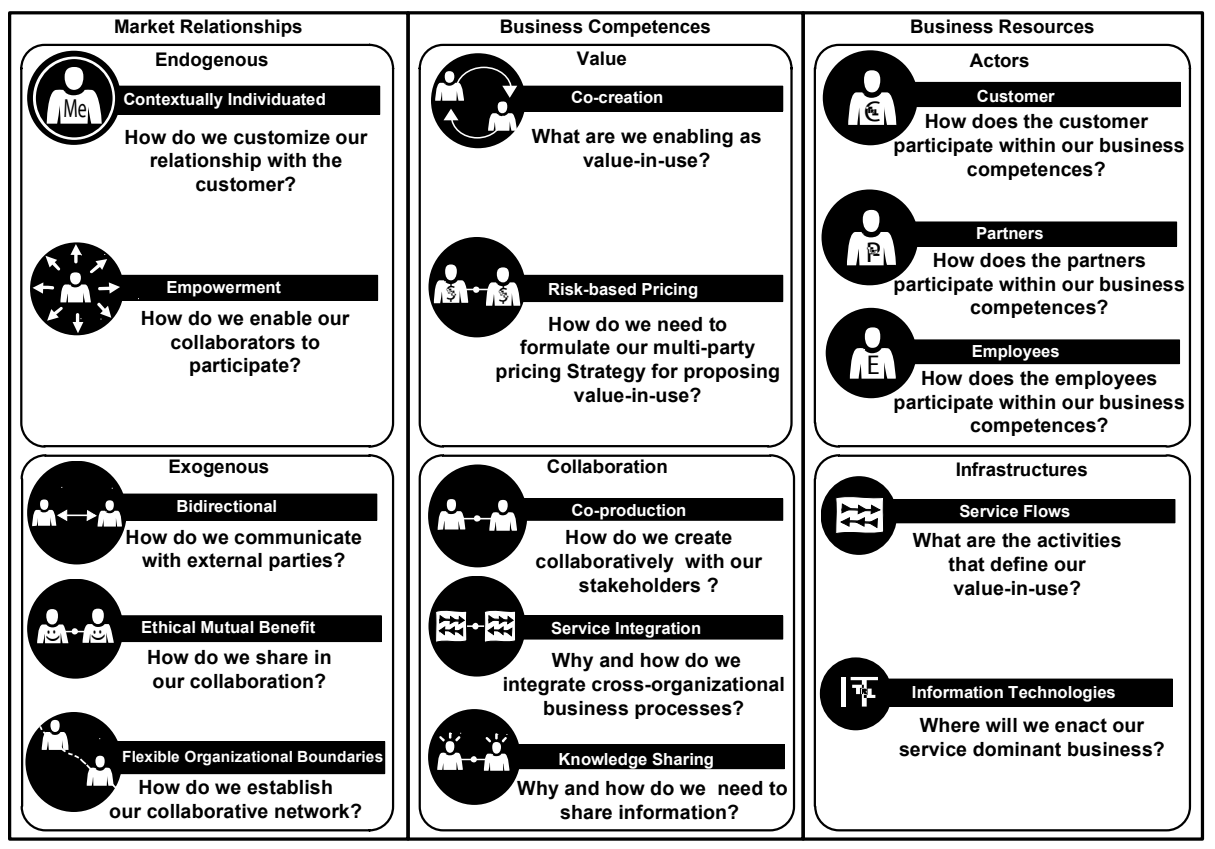

Fig. 1. The Service Dominant Strategy Canvas

As outcome of our qualitative research, we have three strategic canvases. From each of the sessions previously depicted we can conclude the following: in the three tested industry settings, we found that value-in-use explained by the co-creation element was an eye-opener for the participants. This element shifts the mindset from the focus of the good to the service that renders. After this mindset change, strategic canvas achieved successfully to communicate the collaboration perspective. In the case of the logistics industry, we observe that canvas facilitates the focus on a logistic experience where collaborators can participate in the transportation service. In the case of the asset-based finance industry, the mindset change is achieved by moving from asset centered activities towards the activities focused on the usage of the asset. Al last, in the car leasing industry the canvas facilitated the shift from cars toward a customer centric solution enabled by Information Technologies.

The participants were able to deal with the novel aspects of a Service Dominant Strategy. After the first session, we communicated the mindset change and we were able to guide the participants to answer the questions. However, we found out that we need more than just one session to refine the outcome of the filled canvas. This is explained due two main reasons. Firstly, the concept is new for the industry. Secondly, the numerous elements needed for conceptualization of a service dominant strategy. Furthermore, the service dominant strategy will be the basis for their future service dominant business models and service-oriented information systems empowered by collaborative networks. 


\section{Conclusions and Future Work}

In this paper we present the Service Dominant Strategy Canvas as a management tool to facilitate the design of service dominant strategies. In our test sessions, the strategic tool appears to be an innovation catalyst for asset dominant companies towards service orientation. Innovation managers and strategists find the tool useful for defining future strategies.

In a nutshell, the Service Dominant Strategy Canvas facilitates the understanding that solutions require multi-stakeholder perspective enabled by collaborative networks. This strategic perspective is constructed by taking a multidisciplinary approach on service by integrating business, marketing and information systems point of views. The presented canvas is the outcome of the development of the first layer of the Service Dominant Business Logic Framework. This framework is defined by four layers. Firstly, the Strategy layer is the long-term vision that recognizes the Service Dominant strategic paradigm. Secondly, we have the Business layer that takes the networked approach on business models by following the Service Dominant Strategy. Thirdly, we have Organization layer that focuses on the networked processes on the collaborative network. Finally, we have the Systems layer that is focused on a highly modular service-oriented architecture as enabler of our approach. Currently, we are working on the business layer by developing a tool to design Service Dominant Business Models.

\section{References}

1. Spohrer, J., Maglio, P.: The emergence of service science: Toward systematic service innovations to accelerate co-creation of value. Production and Operations Management 17(3), 238-246 (2008)

2. Chesbrough, H.: Open Services Innovation: Rethinking Your Business to Grow and Compete in a New Era. Jossey-Bass, San Francisco (2011)

3. Bettis, R.A., Prahalad, C.K.: The Dominant Logic: Retrospective and Extension. Strategic Management Journal 16(1), 5-14 (1995)

4. Vargo, S.L., Lusch, R.F.: Evolving to a new dominant logic for marketing. Journal of Marketing 68(1), 1-17 (2004)

5. Lusch, R.F., Vargo, S.L., Wessels, G.: Toward a conceptual foundation for service science: Contributions from service-dominant logic. IBM Systems Journal 47(1), 5-14 (2008)

6. Kaplan, R.S., Norton, D.P.: Linking the balanced scorecard to strategy. California Management Review 39(1), 53-79 (1996)

7. Sven, M.L., Voelpel, C., Eckhoff, R.A.: The tyranny of the balanced scorecard in the innovation economy. Journal of Intellectual Capital 7(1), 43-60 (2006)

8. Osterwalder, A., Pigneur, I.: Business Model Generation: A Handbook for Visionaries, Game Changers and Challengers. Willey, New Jersey (2010)

9. Lusch, R.F., Vargo, S.L., O'Brien, M.: Competing through service: Insights from servicedominant logic. Journal of Retailing 83(1), 5-18 (2007)

10. Karpen, I., Bove, L.: Linking S-D logic and marketing practice: Toward a strategic service orientation. In: Otago Forum 2 Proceedings, Univeristy of Otago, pp. 214-237 (2008) 
11. Järvesivu, P.: Constructing a Service-Dominant Strategy: A Practice- Theoretical Study of a Start-Up Company. Ph.D thesis, Aalto University (2010)

12. Lüftenegger, E., Grefen, P., Weisleder, C.: The Service Dominant Strategy Canvas: Defining and Visualizing a Service Dominant Strategy Through the Traditional Strategic Lens. Beta Report, Eindhoven University of Technology (2012)

13. Stabell, C.B., Fjeldstad, Ø.D.: Configuring value for competitive advantage: on chains, shops, and networks. Strategic Management Journal 19(5), 413-437 (1998)

14. Hunt, S., Derozier, C.: The normative imperatives of business and marketingstrategy: grounding strategy in resource-advantage theory. Journal of Business and Industrial Marketing 19(1), 5-22 (2004)

15. Grant, R.: A resource-based theory of competitive advantage: implications for strategy formulation. California Management Review 33(3), 114-135 (1991) 